\title{
O FUTURO DA INTERNET: EM DIREÇÃO A UMA CIBERDEMOCRACIA PLANETÁRIA
}

\section{Márcio Roberto de Lima'}

LEMOS, Andre. LÉVY, Pierre. O futuro da Internet: Em direção a uma ciberdemocracia planetária. São Paulo: Paulus, 2010. 258p.

Pierre Lévy é filósofo e dedica sua agenda acadêmica à compreensão dos desdobramentos cognitivos e culturais das tecnologias digitais, ao estudo da apropriação dessas tecnologias por parte da sociedade contemporânea cibercultura - e à construção do conceito de inteligência coletiva. É professor do departamento de comunicação da Universidade de Ottawa, Canada. André Lemos é sociólogo e atua na área de comunicação e sociologia, com ênfase em cibercultura. É professor associado da Faculdade de Comunicação da Universidade Federal da Bahia, onde atualmente pesquisa a relação entre mobilidade, comunicação, tecnologias sem fios e o espaço urbano.

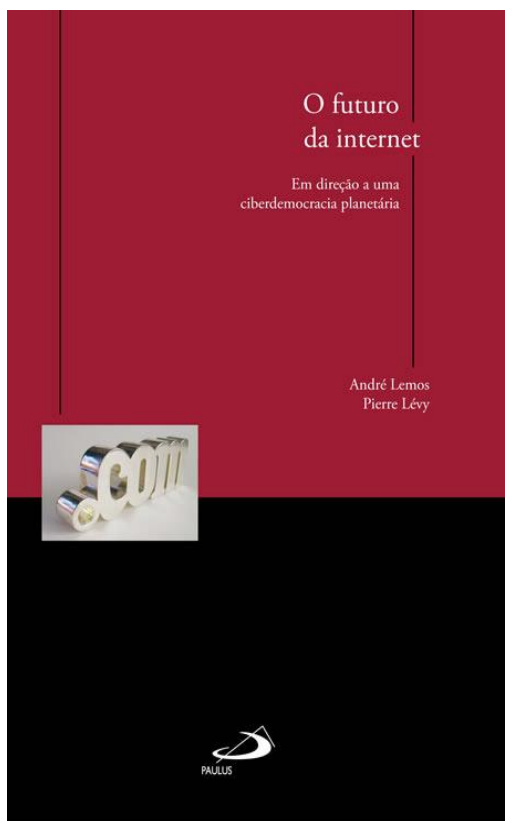

O livro "O futuro da Internet: Em direção a uma ciberdemocracia planetária” é uma tradução intencionalmente modificada por Lemos para a obra "Cyberdérmocracie: Essai de Philosophie Politique" de Lévy, publicada originalmente na França em 2002. As alterações promovidas no original dizem respeito a referências a sítios da internet e a expansão das funcionalidades do ciberespaço com a Web $2.0^{2}$, as quais não existiam ou ainda não haviam se consolidado na época da publicação original. Com 11 capítulos, aborda uma análise das transformações

\footnotetext{
${ }^{1}$ Doutorando em Educação pela Universidade Federal de Minas Gerais (FAE/UFMG), Mestre em Educação pela Universidade Federal de São João del-Rei (UFSJ), graduado em Engenharia Elétrica (UFSJ). Professor do Departamento de Ciências da Educação da (DECED/UFSJ). Áreas de interesse e atuação: Educação e Cibercultura, relações entre as tecnologias digitais da informação e comunicação e a formação docente, sua incorporação nas práticas pedagógicas e nas relações de ensino-aprendizagem. E-mail: marcinholima@ gmail.com.

${ }^{2}$ Blogs, microblogs, redes P2P, redes sociais, ferramentas colaborativas, mídias locativas são alguns exemplos das funcionalidades da Web 2.0.
} 
contemporâneas da esfera pública como resultado da expansão do ciberespaço, salientando perspectivas associadas à democracia.

A publicação enfoca os princípios da cibercultura - liberação da palavra, conexão generalizada e reconfiguração - como a base de um processo de emancipação social rumo à democracia em escala planetária. Para tanto, os autores introduzem a ideia de "aprendizagem coletiva" como uma dinâmica social e comunicacional, regida pela colaboração em rede e suportada pelo ciberespaço. A liberação da palavra é a pluralização de discursos/vozes mediante a conexão generalizada ("tudo em rede"). Da combinação desses fundamentos, emerge a reconfiguração das estruturas sociais, instituições e práticas comunicacionais. De natureza global, a cibercultura revela interatividade, colaboração, possibilidade de intervir e se posicionar frente às demandas sociais, o que favorece os processos de inteligência e aprendizagem coletivas rumo a ciberdemocracia.

Para construir o conceito de ciberdemocracia Lévy e Lemos fazem breve resgate histórico do surgimento da escrita, do alfabeto, da imprensa, do audiovisual e do ciberespaço, destacando a comunicação e a circulação de informações como possibilitadores do Estado e da governança. $\mathrm{O}$ ciberespaço - enquanto meio de convergência de mídias e infraestrutura para a inteligência coletiva - é considerado como um "novo espaço público", onde deve imperar a liberdade de expressão e a livre comunicação. A computação social da Web 2.0 reflete esses pressupostos a partir da escrita coletiva, da aprendizagem e colaboração em rede, ampliando a mobilização cultural e política dos cidadãos. Portanto, a ciberdemocracia seria um aprofundamento e generalização da livre diversidade de saberes, de ideias e recursos em um espaço aberto à comunicação e à cooperação, ou seja: um amalgama entre a liberdade e os processos de inteligência coletiva.

Assim, a apropriação social das funcionalidades pós-massivas do ciberespaço possibilitariam o rompimento do discurso hegemônico - outrora proferido pelos mass media - e criaria condições para uma nova relação entre a esfera pública e a interação comunicativa. Entretanto, os autores repudiam o pensamento de que o surgimento e domínio de uma nova mídia acarretariam automaticamente em novo regime politico. Nesse sentido, ponderam que certas mudanças políticas só são possíveis de serem pensadas/implementadas com mídias acessíveis, abertas e transparentes. 
A mutação das mídias e sua convergência para o ciberespaço é explicada pelos autores com base nos fundamentos da cibercultura, tendo como resultado a reconfiguração da opinião pública. Isso porque a expansão das funcionalidades do ciberespaço - enquanto meio conversacional livre, aberto, multidirecional, interativo e planetário - possibilitaria debates independentes de centros polarizadores. Lemos e Levy consideram em sua análise da reconfiguração midiática a perspectiva global de sua efetivação, a convergência dos suportes da informação e a responsabilidade dos atores sociais no processo, apontando iniciativas emergidas com a computação social: citzen journalism, mobile journalism ou locative journalism. Dessa forma, a nova "ecologia" midiática é caracterizada como um sistema onde quaisquer interessados produzem colaborativamente informação, revelando processos coletivos, inteligentes e independentes.

A grande mutação das mídias encerra a transição do "tempo real e único" das mídias massivas em um "tempo ampliado e diferido", ou seja: acrescenta-se à dimensão da informação os aspectos da livre escolha dos "usuários", da memória contínua e ampliada (recuperação da informação) e do acesso globalizado e vivo (fusão dos sujeitos consumidores-produtores). Estabelecendo um paralelo entre como as funções massivas da mídia moldaram a democracia nos séculos XVIII, XIX e XX, os autores indicam as funcionalidades pós-massivas do ciberespaço como elementos capazes de viabilizar a transformação da democracia em ciberdemocracia na contemporaneidade. A liberação da emissão em rede associada a interesses comunitários inspiram a reconfiguração da esfera pública.

Os autores não negligenciam um possível caos informativo frente ao enorme e crescente volume de informações que existem na Web. Seguem, então, os questionamentos: como filtrar/validar as informações disponibilizadas? Estaríamos à mercê dos códigos matemáticos dos motores de busca? A ideia dos autores é que a associação de internautas em redes colaborativas aliadas às capacidades de pesquisa nos mecanismos taxonômicos facilitaria a emergência de um sistema de mediação participativa, pelo qual os próprios produtores/leitores imputariam reputação à informação de interesse. Esse novo processo de mediação vem sendo adotado por parte da comunidade científica, como o Laboratório Nacional de Física Nuclear de Los Alamos/EUA, que passou a acolher todos os artigos submetidos para publicação sem seleção a priori. Em contrapartida, o Laboratório promove o recenseamento do número de citações 
desses artigos e também de seus comentários, configurando uma seleção a posteriori baseada na participação colaborativa em rede e na relevância dos conteúdos para os interagentes.

Na cultura digital, o aumento exponencial de conteúdo propiciado pela liberação do polo da emissão é encarado na publicação como atestado do vitalismo social e expansão da inteligência coletiva. Portanto, vivemos na cultura que permite o luxo da escolha, do excesso, da garimpagem e da profusão contínua, constituindo um universo de possibilidades que rompe com a tradição hegemônica massiva.

As comunidades/redes sociais são consideradas na obra como o fundamento social do ciberespaço e chaves para a ciberdemocracia. Isso porque quando convenientemente organizadas representariam núcleos ricos em produção e compartilhamento de conhecimento, tendendo à inteligência coletiva.

Paralelo às comunidades virtuais emergem as cibercidades - um hibridismo entre o espaço físico e eletrônico. As cibercidades englobam as iniciativas de infraestrutura de acesso público em área urbana às redes telemáticas, projetos de representação na web de uma determinada localidade (incluindo serviços, informações gerais, representação política etc.), modelagem geográfica para processamento de dados espaciais e, também, comunidades virtuais que usam a metáfora da cidade para a organização do acesso às informações. Essas entidades virtuais fomentam a instauração de diferentes formas de comunicação virtual e reapropriação do espaço físico, favorecendo a apropriação social das tecnologias digitais e a ciberdemocracia.

A governança eletrônica também é analisada no livro, sendo apontada como uma forma de conferir eficácia ao setor público, simplificar procedimentos administrativos tornandoos mais transparentes e acessíveis aos cidadãos. É com esse espírito que são ilustrados diferentes iniciativas de e-government, inclusive no Brasil: Portal da transparência ${ }^{3}$, Governo Eletrônico Brasileiro $^{4}$, Portal da Presidência ${ }^{5}$ etc.

O voto eletrônico via internet é considerado pela dupla de autores como uma consequência do processo de expansão da inteligência coletiva no ciberespaço, requerendo ampla rede de infraestrutura com sofisticada segurança digital. Nesse sentido, a inclusão digital é apresentada como uma questão que caminha juntamente com o combate a pobreza e ao

\footnotetext{
${ }^{3}$ http://www.portaldatransparencia.gov.br/

${ }_{5}$ http://www.governoeletronico.gov.br/

5 http://www.presidencia.gov.br/
} 
analfabetismo, pois se não enfrentada com determinação contribuiria para o aumento dessas mazelas sociais.

Embora admitam a inexistência de condições necessárias para sua efetivação, Lemos e Lévy apresentam argumentos referentes à estruturação de um governo leis e justiça de ordem planetária. Essa perspectiva incipiente e ambiciosa refletiria na ordenação da economia mundial, na preservação do ecossistema terrestre e, obviamente, nos rumos da ciberdemocracia. De forma assumidamente utópica (p.183), os autores introduzem seu ensaio teórico do Estado transparente como uma forma de governança alinhada à civilização planetária da inteligência coletiva. $\mathrm{O}$ estado universal e seus fundamentos jurídicos e econômicos são problematizados em torno de três tendências atuais: a globalização, a expansão do liberalismo econômico e a interconexão, que favorece significativamente a inteligência coletiva.

Os autores elencam a diversidade cultural na cibercultura e propõem uma discussão sobre sua uniformização em tempos de interconexão planetária. Alertam para o fato de que o ciberespaço possibilita unidade sem necessária uniformidade, apostando no crescimento da diversidade cultural. Argumentam que a multiplicação das formas de comunicação resultou, igualmente, na ampliação de gêneros literários, artísticos, científicos etc., e não o contrário. Defendem, portanto, que o ciberespaço não foge a essa regra e que desse movimento pluricultural emerge o homem cosmopolita de identidade planetária.

Levy e Lemos terminam o livro evocando a dimensão ética para a inteligência coletiva e seus processos correlatos, configurando a ciberdemocracia como arte do diálogo aberto, responsável e plural. Destacam que as grandes etapas da evolução cultural da humanidade correspondem a mutações na linguagem em seus diferentes formatos. Argumentam que a escrita deu à linguagem uma memória, que o alfabeto tornou a escrita universal, que a imprensa possibilitou a reprodução automática da linguagem e que o ciberespaço instrumentaliza a expansão ilimitada da inteligência coletiva.

A leitura de "O futuro da Internet: Em direção a uma ciberdemocracia planetária" suscita, em alguns trechos, o incômodo de estar de frente a um texto utópico. Entretanto, o continuum de reconfigurações que é inerente à cibercultura não permite as linhas esquadrejadas de um projeto para o seu devir, quiçá seu esboço. Pensar o futuro requer ousadia e um olhar sem preconceitos. Esse parece ser o caminho escolhido por André Lemos e Pierre Lévy. Em seu conjunto a obra atualiza a visão dos autores sobre a cibercultura, novas funcionalidades do 
ciberespaço e o próprio conceito de inteligência coletiva, ensaiando uma teoria para a política que visa dar sentido à ciberdemocracia em escala planetária. 